\title{
IMPACTO DA VINCULAÇÃO E DOS TRAÇOS DE PSICOPATIA NOS COMPORTAMENTOS ADITIVOS DOS ADOLESCENTES
}

\author{
Ana Rita Silva ${ }^{1} \odot$, Inês Carvalho Relva $\odot, \&$ Margarida Simões ${ }^{2} \odot$ \\ Universidade de Trás-os-Montes e Alto Douro, Vila Real, Portugal. ${ }^{3}$
}

\begin{abstract}
RESUMO
O presente estudo analisou a relação entre o consumo de substâncias (medido pelo DAST), a vinculação aos pais e grupo de pares (medida por meio do IPPA-R) e um conjunto de traços psicopáticos (avaliados a partir do YPI-RE). Trata-se de um estudo quantitativo e transversal, sendo a amostra constituída por 317 adolescentes que frequentavam as escolas públicas da região Norte do país. Os resultados sugerem um efeito preditor dos traços de psicopatia no consumo de drogas por parte do adolescente. Sugerem, também, uma média de consumo superior para os adolescentes entre os 15 e os 18 anos de idade, não tendo as análises revelado diferenças significativas no consumo relativamente ao sexo do adolescente. Sugerem, ainda, uma correlação negativa entre o consumo de substâncias e as dimensões da vinculação avaliadas. Os resultados do presente estudo chamam a atenção para a importância de uma intervenção em faixas etárias cada vez mais precoces.
\end{abstract}

Palavras-chave

adolescência; padrões de vinculação; consumo de drogas; psicopatia

\begin{abstract}
The present study examined the relationship between substance use (measured by DAST) and attachment to parents and peer group (measured through IPPA-R), and a set of psychopathic traits (assessed through YPIRE). This was a quantitative and cross-sectional study, and the sample consisted of 317 adolescents who attended public schools in the northern region of the country. The results suggest a predictive effect of psychopathy traits on adolescent drug use. They also suggest a higher average consumption for adolescents between 15 and 18 years of age, and the analyzes did not reveal significant differences in consumption in relation to the adolescent's gender. They also suggest a negative correlation between substance use and the dimensions of the attachment evaluated. The results of the present study draw attention to the importance of an intervention in increasingly early age groups.
\end{abstract}

\section{Keywords}

adolescence; attachment patterns; drug use; psychopathy

\footnotetext{
${ }^{1}$ Correspondence about this article should be addressed to Ana Rita Silva: ana13-g-s@hotmail.com

${ }^{2}$ Centro de Investigação em Desporto, Saúde e Desenvolvimento Humano, Universidade de Trás-os-Montes e Alto Douro.

${ }^{3}$ Departamento de Educação e Psicologia - Edifício da Escola de Ciências Humanas e Sociais - Polo I, Quinta dos Prados - UTAD, 5000-801 Vila Real, Portugal.
} 


\section{IMPACT OF ATTACHMENT AND TRAITS OF PSYCHOPATHY ON ADDICTIVE BEHAVIORS OF ADOLESCENTES}

A adolescência é uma fase da vida em que ocorrem diversas modificações a vários níveis, nomeadamente ao nível psíquico, social e corporal. Os adolescentes pretendem desenvolver um relacionamento mais maduro com os seus pais, mútuo e menos dependente, adquirindo os seus próprios valores (Ferronha, Almeida, Oliveira, Sousa, \& Sousa, 2014). Esta necessidade de separação permite-lhes ter a sua própria visão do mundo, considerar diferentes opções para o futuro, projetos e desejos. Posto isto, é necessário ocorrer uma revisão de limites e papéis sociais na família (Brandão, 2013). É nesta fase que as necessidades de vinculação passam a ser direcionadas para o grupo de pares. $\mathrm{O}$ adolescente começa a deixar de ser só um recetor de cuidados para também se tornar um prestador de cuidados (Ferronha et al., 2014). As necessidades de vinculação do jovem não desaparecem, mas passam a ter outros significados e a existir outras figuras vinculativas (Ferronha, Teixeira, \& Souto, 2008).

No que diz respeito à vinculação, esta deriva dos trabalhados realizados por Ainsworth e Bowlby (1991) é originária da psicologia do desenvolvimento e da psicanálise. A teoria pressupõe que a ligação de uma mãe com o filho bebé serve de base para os seus relacionamentos futuros. Essa vinculação ajuda, ainda, a promover expectativas em relação a si e aos que o rodeiam. Isto apresenta influência sobre a socialização e a emocionalidade do indivíduo no decorrer da sua vida. Além do mais, é relevante na regulação psicobiológica e por formar um modelo de relações interpessoais alicerçadas na confiança básica (Ferronha et al., 2014). Desta forma, é dado especial ênfase ao estabelecimento da primeira relação com as figuras de vinculação (Ferreira \& Pinho, 2009).

Existem algumas características que podem ser apontadas como facilitadoras de uma vinculação segura e desenvolvimento de autonomia por parte do adolescente. São elas, disponibilidade psicológica; atenção prestada ao comportamento, mas também a capacidade de colocar limites ao mesmo; capacidade de escutar; e a aceitação por parte dos pais da individualidade do adolescente de modo que este se sinta aceite tal como é (Ferronha et al., 2014).

Os adolescentes ao apresentarem uma vinculação segura aos pais torna benéfico o facto de aventurarem-se no mundo complexo da emocionalidade adulta. Ou seja, esta dá aos jovens a coragem de se tornarem mais autónomos embora proporcionando-lhes uma base segura de suporte emocional. (Ferronha et al., 2008). É sabido que a família, a sua estrutura, 
as relações que ocorrem no seu seio e as influências por estas exercidas, são considerados fatores de risco para o adolescente adotar comportamentos desviantes (Ferros, 2003). E, sendo esta um agente fundamental na estruturação da personalidade e socialização do adolescente, ocupa uma posição primordial para compreender o consumo de drogas (Gonçalves \& Pereira, 2011).

Droga pode ser definida como toda e qualquer substância não produzida pelo organismo e que quando introduzida neste interfere com o seu funcionamento produzindo alterações (Brandão, 2013). A adição é um fenómeno biopsicossocial, em que vários fatores interagem, contribuindo para a criação de condições que promovem o seu aparecimento (Ferros, 2003).

O consumo está relacionado com relações complicadas no seio familiar, com a falta de vínculos afetivos positivos, falta de confiança e padrões de comunicação pouco definidos (Gonçalves \& Pereira, 2011). Quanto ao grupo de pares este pode funcionar como agente de favorecimento do consumo de drogas, mas também como agente de ajuda e proteção. $\mathrm{Ou}$ seja, a rede social do adolescente pode despertar o seu interesse por hábitos não saudáveis, associados ao consumo de drogas. Todavia, no caso desta rede social não compartilhar desse uso, isso funcionará como uma ajuda para a proteção do adolescente (Brandão, 2013). O grupo de pares exerce, assim, especialmente uma pressão social sobre o adolescente no sentido da conformidade ao grupo (Dietz, Santos, Hildebrandt, \& Leite, 2011). Sem dúvida que a família e, também, o grupo de pares são considerados como grandes responsáveis (grande influência) no que diz respeito ao consumo de drogas pelo adolescente. Isto acontece uma vez que são vistos como modelos comportamentais.

A Teoria da Aprendizagem Social de Bandura (1977) é uma das teorias mais utilizadas e importantes dentro do campo das drogadições. Esta aponta o consumo de drogas como um comportamento aprendido, automatizado, que é desencadeado e preservado por acontecimentos e emoções particulares e suscetível de ser alterado. Este autor propõe que a aprendizagem ocorre pela observação do comportamento de outrem e suas consequências e, que posteriormente, servirá como um guia de ações. Assim, torna-se fundamental referir o conceito de modelagem, sobretudo no que respeita ao consumo de substâncias. É de salientar que não se trata de uma mera imitação, uma vez que o indivíduo avalia o comportamento e tem a possibilidade de o reproduzir ou não (Pechansky, 2001). 
Outra das teorias que importa referir é o modelo evolutivo de Kandel (1975). Este modelo apresenta como base a teoria da socialização ou focada (foca na influência dos pais e pares no desenvolvimento dos adolescentes) e faz referência à sequência de evolução do consumo de drogas, que parte de uma fase de iniciação em que há um consumo de drogas legais até um consumo de drogas ilegais. É importante considerar ainda os elementos com os quais o sujeito se relaciona para conhecer melhor o seu processo de socialização. Assim, o consumo é resultado da interação entre características individuais e influências sociais.

Existem alguns fatores que podem ser apontados como protetores em relação ao consumo. São eles: vinculação segura com os pais, limites bem estabelecidos e existência de suporte parental, ambiente positivo em casa, forte aceitação parental das crenças sobre o que deve ser o bom comportamento adolescente, forte desaprovação de eventuais comportamentos indesejáveis e ausência de consumos nos irmãos, pais e pares (Ferros, 2003).

Num estudo realizado por Ferronha et al. (2008) com um grupo de 17 adolescentes toxicodependentes e um grupo de 445 adolescentes não toxicodependentes de diversas escolas do Norte de Portugal, tendo por objetivo perceber se existiam diferenças na vinculação entre os dois grupos, chegou-se à conclusão que a vinculação aos pais do grupo de toxicodependentes era notoriamente mais insegura que a do outro grupo. Fonseca (2010) realizou um estudo longitudinal em adolescentes portugueses em diferentes fases (antes, durante e no fim da adolescência), em que aplicou um questionário relativamente à perceção da vinculação aos pais, tendo sido possível concluir que existia uma relação negativa considerável entre a perceção da vinculação aos pais e consumo de droga. Assim, quanto melhor (mais positiva) a perceção da relação com os pais, menor o consumo de droga referido. Os resultados permitiram confirmar ainda que o consumo é influenciado pelo grupo de pares também consumidor.

Segundo dados do DMS-V (Diagnostic and Statistical Manual of Mental Disorders), o consumo de drogas está também associado à personalidade psicopática, atualmente conhecida por perturbação de personalidade antissocial (Lühring et al., 2014). O termo "Psicopatia" deriva do grego e significa "psiquicamente doente". O conceito surgiu com Pinel em 1809 e expressa-se num conjunto de condutas resultantes quer de fatores biológicos quer da personalidade, que estão relacionados com variados antecedentes familiares e fatores ambientais. A psicopatia faz-se acompanhar por comportamentos marcadamente antissociais (Soeiro \& Gonçalves, 2010). 
McCords (1959/1964), juntamente com Cleckley (1941), e Karpman (1949, 1950) foram os pioneiros no que respeita a questões relacionadas com a psicopatia em crianças e adolescentes, nomeadamente se esta existe nestas idades, quando pode ser identificada, se apresenta uma causa biológica ou ambiental e a possível existência de tratabilidade (Salekin \& Lynam, 2010).

Também Salekin (2002) acredita na existência de fortes razões para a presença de psicopatia na adolescência. Foi na década de 1990, com a adaptação do Psychopathy Checklist-Revised (PCL-R), que se verificou um aumento dos estudos relativamente à vertente da psicopatia para a população jovem, devido aos avanços no estudo da psicopatia em adultos. Contudo, várias questões continuaram a ser levantadas (aplicabilidade do constructo em jovens dada a sua natureza pejorativa; se as manifestações do constructo eram semelhantes nos diferentes níveis de desenvolvimento e semelhante à psicopatia na fase adulta). Mais se acrescenta que, o termo psicopatia por vezes transmite um padrão de personalidade biologicamente determinado, estável e intratável, sendo assim algo muito questionável e controverso quando se trata de crianças e adolescentes (Salekin \& Frick, 2005). Além de que, algum nível de psicopatia pode ser considerado normativo na juventude, correndo o risco de rotular alguns jovens que apresentam somente um padrão de comportamento transitório

Foi realizado um estudo com o intuito de avaliar a existência de traços de psicopatia (a partir da PCL:YV - Psychopathy Checklist: Youth Version) numa amostra de 226 adolescentes (de ambos os sexos) institucionalizados com idades compreendidas entre os 12 e os 19 anos. Os resultados permitiram encontrar um grupo de cerca de 21 adolescentes que tinham pontuado um total de 25 ou mais pontos no PCL:YV, ou seja, revelando elevados valores de psicopatia (Campbell, Porter, \& Santor, 2004).

McCord e McCord (1959/1964) na obra O Psicopata: Um Ensaio Sobre a Mente Criminosa, ressaltaram precisamente a importância de identificar e tratar precocemente a psicopatia na população jovem. Foi observado por estes que a perturbação era diferente da que se apresentava noutros jovens com problemas comportamentais, tendendo a ser mais rara (somente $14 \%$ dos jovens infratores apresentavam sinais de uma perturbação de personalidade psicopática). Salekin (2002) aponta a necessidade de serem realizados esforços complementares no que respeita aos estudos com jovens, por forma a tentar 
compreender os fatores neurológicos, biológicos, psicológicos e sociais que originam e mantém a personalidade psicopática.

No que remete para a associação entre psicopatia e consumo, estudos realizados demonstram a ligação entre estas duas variáveis. A partir de análises realizadas entre o PCL$\mathrm{R}$ e os diagnósticos de abuso de substâncias (álcool ou outras drogas) obtiveram-se correlações positivas que variaram entre .24 e .40 , tendo sido o estilo de vida antissocial que contribuiu maioritariamente para estas correlações (Hare, 1991). No estudo de Fonseca (2010) anteriormente citado, um dos resultados obtidos aponta precisamente para a existência de uma elevada correlação entre consumo de drogas e comportamento antissocial. Cerca de 95\% das pessoas com perturbação de personalidade antissocial, são dependentes de álcool ou outras drogas, sendo que $30 \%$ apresenta um consumo de uma ou mais substâncias. Mais se acrescenta que, é habitual um dependente de substâncias químicas desenvolver comportamentos antissociais. Lühring et al. (2014) realizaram um estudo com o intuito de perceber a correlação entre traços de psicopatia e abuso de drogas, constituído por 185 adolescentes brasileiros do sexo masculino entre os 12 e os 18 anos. Verificou-se que os que apresentaram médias superiores relativas aos traços de psicopatia eram os que faziam uso mais intensivo de drogas, sugerindo os resultados obtidos a existência de relação entre consumo e psicopatia.

Também Fonseca (2013) realizou um estudo com 445 alunos avaliados em quatro momentos diferentes do desenvolvimento entre os 7 e os 18 anos de idade, no que respeita à relação entre o consumo de drogas e comportamentos antissociais durante a adolescência. Constatou-se que os comportamentos antissociais e o consumo estavam amplamente associados durante todo o período da adolescência. Mais concretamente, o comportamento antissocial numa fase intermédia da adolescência predizia de alguma forma o consumo aos 17-18 anos de idade (Fonseca, 2013).

Face ao exposto e à escassez de estudos que explorem as variáveis aqui apresentadas, o presente estudo avalia o impacto que a vinculação e os traços psicopáticos têm no consumo de drogas. Ou seja, verificar se os diferentes padrões de vinculação estão associados com o consumo e se um conjunto de traços psicopáticos podem também eles ser explicativos da adição. Assim, e de forma mais específica pretende-se: a) explorar a existência de diferenças no consumo consoante a faixa etária do adolescente; b) analisar possíveis diferenças no consumo consoante o sexo do adolescente; c) analisar as relações existentes entre o consumo e as dimensões do YPI-RE e do IPPA-R; d) explorar o efeito preditor de um conjunto de 
traços psicopáticos no consumo de substâncias; e e) em que medida a vinculação às figuras significativas poderá predizer o maior ou menor consumo por parte do adolescente.

\section{Método}

Este estudo é de caráter quantitativo, pretendendo quantificar fenómenos por meio de procedimentos estatísticos. Baseia-se no paradigma correlacional, uma vez que é pretendido compreender o grau e a forma de associação entre as variáveis analisadas. Ou seja, permite perceber o comportamento de uma variável, conhecendo o comportamento de outras. É, ainda, um estudo de cariz transversal, dado as variáveis terem sido medidas num único espaço temporal e de comparação entre indivíduos (Marôco, 2007).

\section{Participantes}

A amostra foi constituída inicialmente por 320 participantes, sendo que posteriormente foi reduzida para 317 após ter sido efetuada uma limpeza amostral. Dos 317 participantes, 183 eram do sexo feminino (57.7\%) e 134 do sexo masculino (42.3\%), com idades compreendidas entre os 12 e os 18 anos, apresentando uma média de idades de 15.79 com desvio-padrão de 1.659. Quanto ao ano de escolaridade, 99 alunos eram do $11^{\circ}$ ano, 70 do $10^{\circ}$ ano, 61 do $12^{\circ}$ ano, 41 do $7^{\circ}$ ano, 25 do $9^{\circ}$ ano e 21 do $8^{\circ}$ ano. Destes, 287 eram do ensino regular e 30 do ensino profissional. O meio de residência foi maioritariamente rural (129) seguido de semiurbano (102) e, posteriormente, urbano (86). O estado civil das figuras parentais (ou respetivos substitutos) da maioria dos participantes eram casados (255) e, na sua maioria, as habilitações literárias da figura paterna eram o $3^{\circ}$ ciclo (89) e o secundário (71) e no caso da figura materna o secundário (86) e ensino superior (77). Para a recolha de dados foi pedida a colaboração de instituições de ensino da região Norte de Portugal.

\section{Instrumentos}

Questionário sociodemográfico - Elaborou-se um questionário de recolha de informações relativas ao sexo, idade, ano de escolaridade, tipo de ensino, meio de residência, estado civil das figuras parentais e respetiva escolaridade.

Inventory of Parent Peer Attachment (IPPA-R) - Instrumento selecionado para avaliar a vinculação existente ao pai, mãe e grupo de pares, concebido por Gullone e Robinson (2005). A versão original do instrumento, designada IPPA é de Armsden e 
Greenberg (1987). O IPPA-R foi adaptado e validade para a população portuguesa por Machado e Figueiredo (2010). No presente estudo foi utilizada a versão em português de Simões, Lara, Lourenço e Martins (2018) para adolescentes entre os 12 e os 18 anos de idade. O instrumento apresenta três versões: mãe (constituído por 26 itens), pai (constituído por 26 itens) e pares (constituído por 25 itens). Estes itens avaliam três dimensões diferentes relacionadas com a vinculação. São elas a comunicação, a confiança e a atenção/alienação. O tipo de resposta é no formato Likert em três pontos relativamente à classificação das respostas (1- nunca; 2- às vezes e 3- sempre). O instrumento revela características psicométricas adequadas, exibindo índices de consistência interna iguais ou superiores a .80, comprovando assim que este é um instrumento fiável. Foram analisados os índices de modificação de ajustamento deste instrumento na presente amostra e os valores obtidos revelaram-se adequados. Para a versão da mãe obteve-se um $\chi^{2 / \mathrm{df}}=2.380, \mathrm{GFI}=.85, \mathrm{CFI}=$ .90 e RMSEA $=.06$. Para a versão do pai obteve-se um $\chi^{2 / \mathrm{df}}=3.159, \mathrm{GFI}=.80, \mathrm{CFI}=.90 \mathrm{e}$ RMSEA $=.08$. Para a versão pares obteve-se um um $\chi^{2} / \mathrm{df}=2.528, \mathrm{GFI}=.84, \mathrm{CFI}=.90 \mathrm{e}$ RMSEA $=.07$. Os valores do GFI deste instrumento encontram-se abaixo de .9 , contudo o GFI e o AGFI são conhecidos por dependerem do tamanho da amostra (Mulaik et al., 1989). O alpha de Cronbach deste instrumento para a presente amostra foi de .92 para a versão mãe, .94 para a versão pai e de .92 para a versão pares.

Youth Psychopathic Traits Inventory Reconstruted (YPI-RE) - Para avaliar a existência de um conjunto de traços psicopáticos na presente amostra foi utilizado este instrumento de autorrelato, que apresenta como objetivo identificar traços psicopáticos entre os 12-18 anos de idade. É constituído por 10 dimensões (charme-falso, grandiosidade, mentira, manipulação, ausência de remorsos, ausência de emotividade, frieza emocional, busca de perigo, impulsividade e irresponsabilidade) e três superdimensões (insensibilidade, manipulação interpessoal e impulsividade), distribuídas por 50 itens. $\mathrm{O}$ formato de resposta é em escala de Likert de cinco pontos, variando de "Nunca" a "Sempre". Este instrumento é útil, pois ajusta-se bem ao modelo teórico da psicopatia e os itens que o constituem estão formulados de maneira a detetar possíveis respostas insinceras. Os itens do YPI-RE, na amostra original, apresentam-se distribuídos em quatro fatores. O primeiro apresenta um alpha de Cronbach de .92, sendo constituído pelas dimensões charme falso $(\alpha=.71)$, grandiosidade $(\alpha=.81)$, mentira $(\alpha=.88)$ e manipulação $(\alpha=.85)$. O fator dois apresenta um alpha de Cronbach de .87, sendo constituído pelas dimensões busca de perigo $(\alpha=.79)$, impulsividade $(\alpha=.81)$ e irresponsabilidade $(\alpha=.75)$. O fator três apresenta um alpha de 
Cronbach de .79, constituído pelas dimensões ausência de emotividade $(\alpha=.70)$ e ausência de remorso $(\alpha=.71)$. Por fim, o fator quatro apresenta um alpha de Cronbach de .83, sendo constituído pela dimensão frieza emocional $(\alpha=.83)$. Assim, o instrumento apresenta índices de consistência interna apropriados e fiáveis (Simões \& Relva, em preparação). Foram, ainda, examinados os índices de modificação de ajustamento deste instrumento na presente amostra e os valores obtidos revelaram-se adequados (Marôco, 2014) $\left(\chi^{2} / \mathrm{df}=1.848\right.$, GFI= $.79, \mathrm{CFI}=.87$ e RMSEA= .05$). \mathrm{O}$ valor do GFI deste instrumento encontra-se abaixo de .9 , contudo o GFI e o AGFI são conhecidos por dependerem do tamanho da amostra (Mulaik et al., 1989). No que respeita aos alphas de Cronbach da presente amostra, obteve-se um valor de .92 para o fator 1 , de .88 para o fator $2, .80$ para o fator 3 e .82 para o fator 4 .

Drug Abuse Screening Test (DAST) - Instrumento que serviu de auxílio para avaliar o possível envolvimento com drogas. Fundamentalmente aborda as diferentes consequências relacionadas com o consumo (sintomas psicológicos e físicos, aspetos socio-relacionais, entre outros) nos últimos 12 meses, produzindo um índice quantitativo de gravidade do problema/consumo. O instrumento é constituído por 20 itens e apresenta uma escala de resposta do tipo dicotómica (Sim/Não). A versão original pertence a Skinner (1982) e apresenta um alpha de Cronbach de .95, revelando uma excelente consistência interna. $\mathrm{Na}$ presente investigação foi utilizada uma versão adaptada para adolescentes e traduzida para o português de Portugal, realizada num estudo em associação com este. $\mathrm{O}$ valor de consistência interna obtido nesse estudo foi de .76, sendo considerado satisfatório e adequado para ser usado de forma fiável. Foi, ainda, realizada uma análise fatorial confirmatória do instrumento para a presente amostra e os valores obtidos nos índices de modificação de ajustamento revelaram-se adequados (Marôco, 2014) $\left(\chi^{2 / \mathrm{df}}=2.751\right.$, $\mathrm{GFI}=.98, \mathrm{CFI}=.98$ e RMSEA=.07). O alpha de Cronbach para a presente amostra foi de .89 .

\section{Procedimento}

Inicialmente a presente investigação foi submetida à Comissão de Ética da Universidade de Trás-os-Montes e Alto Douro, obtendo parecer favorável quanto à sua realização.

Os dados para a presente investigação foram recolhidos em escolas públicas da região Norte de Portugal. Primeiramente realizou-se um pedido à Direção-Geral de Educação (DGE) para que o estudo apresentasse permissão para ser realizado e seguidamente foi 
pedida a colaboração junto dos diretores dos agrupamentos das instituições, esclarecendo o objetivo da investigação, que de acordo com a idade estipulada (dos 12 aos 18 anos), nos indicasse as turmas selecionadas para o efeito. Posteriormente foi entregue o consentimento informado aos encarregados de educação para que estes tomassem conhecimento da investigação e autorizassem os seus educandos a participar no estudo (isto no caso dos adolescentes que ainda não tinham completado os 18 anos de idade. Para os que já tinham o consentimento foi entregue ao próprio). Por fim, foi agendado um dia junto dos diretores de turma para que se procedesse à aplicação dos questionários. Nos documentos entregues foi mencionado a garantia de confidencialidade dos dados recolhidos, respeitando os princípios deontológicos de investigação em ciências sociais. Os dados foram recolhidos durante os meses de maio e junho de 2018. O preenchimento dos questionários apresentou uma duração de aproximadamente 25 minutos. Foram também incluídas no questionário variáveis sociodemográficas como sexo, idade, ano de escolaridade, tipo de ensino, meio de residência, estado civil e escolaridade dos pais. O protocolo foi aplicado pela primeira autora do estudo, cuja ordem dos instrumentos foi a seguinte: questionário sociodemográfico, questionário relativo à vinculação às figuras parentais e grupo de pares, questionário relativo à presença de traços de psicopatia e, por fim, questionário referente ao possível envolvimento com drogas. Após todos os dados recolhidos, estes foram inseridos numa base de dados para a concretização das devidas análises estatísticas, recorrendo-se aos softwares SPSS (IBM SPSS Statistics, versão 25) e ao AMOS (IBM SPSS AMOS, versão 25).

\section{Estratégias de análise de dados}

Inicialmente, com o intuito de identificar e excluir eventuais missings e outliers, procedeu-se à limpeza da amostra. Seguidamente, as variáveis de cada instrumento em estudo foram categorizadas, tendo-se procedido à inversão de alguns itens, de acordo com os autores originais. De referir que se verificou a normalidade dos dados, uma vez que a presente amostra é constituída por mais de 30 indivíduos. Após terem sido assegurados os pressupostos de normalidade, procedeu-se às análises estatísticas. Foi ainda calculado o grau de consistência interna das dimensões em análise recorrendo ao Alpha de Cronbach com o objetivo de perceber se os instrumentos utilizados eram fiáveis perante a amostra recolhida. Assim, valores de Alpha de Cronbach superiores a .90 indicam uma consistência interna muito boa, entre .80 e .90 boa, entre .70 e .80 satisfatória e inferiores a .60 baixa consistência. Seguidamente, recorrendo ao AMOS (IBM SPSS AMOS, versão 25), realizaram-se análises 
fatoriais confirmatórias dos modelos representativos dos instrumentos usados na investigação para apurar a adequabilidade destes no que respeita aos seus índices de modificação de ajustamento. Para os modelos testados foi utilizado o método de estimação maximum likelihood. Para verificar a adequabilidade do modelo aos dados foram então usadas as seguintes medidas de avaliação do ajustamento: Ratio chi square statistics/degrees of fredoom ( $\left.\chi^{2} / \mathrm{df}\right)$, Comparative fit índex (CFI), Goodness of fit índex (GFI) e Root mean square error of approximation (RMSEA). De referir que, valores de $\chi^{2} / \mathrm{df}$ superiores a 5 são considerados maus, entre 3 e 5 sofríveis, entre 1 e 2 bons e valores de aproximadamente 1 são considerados muito bons. Quanto ao GFI e CFI, valores inferiores a .8 são considerados maus, entre .8 e .9 sofríveis, entre .9 e .95 bons e iguais ou superiores a .95 muito bons. $\mathrm{O}$ RMSEA considera-se inaceitável se apresentar um valor superior a .10, aceitável entre .06 e .10 e muito bom se apresentar um valor igual ou inferior a .05 (Marôco, 2014).

De seguida, realizou-se a análise de estatísticas descritivas referentes à amostra em estudo, envolvendo o cálculo de frequências, médias e desvio-padrão. Após a análise descritiva, realizaram-se as análises de comparações de médias (Teste t de Student) para apurar possíveis diferenças no consumo relativas à idade e sexo do adolescente. Ainda relativamente à idade e ao sexo, foram analisadas as diferenças no que respeita às dimensões do YPI-RE e do IPPA-R avaliadas. Associada às análises de comparação de médias, realizou-se uma outra análise no sentido de perceber a proporção de variância da variável dependente explicada pela variável independente. Assim, utilizou-se o valor obtido por meio do Partial Eta-square. Cohen (1988), aponta intervalos para a sua interpretação. Entre .1 e .6 considera-se um efeito baixo, entre .7 e .14 de efeito moderado e acima de .14 efeito elevado. Seguidamente, realizaram-se as análises correlacionais a partir do $\mathrm{r}$ de Pearson para perceber a maior ou menor associação entre as variáveis em análise (entre o DAST e o YPI-RE e entre o DAST e o IPPA-R). A interpretação da intensidade das correlações foi realizada tendo por base os intervalos propostos por Cohen (1988). Assim, valores entre .10 e .29 são considerados baixos, valores entre .30 e .49 medianos e entre .50 e 1 elevados. Por fim, efetuou-se uma regressão hierárquica múltipla no sentido de verificar o poder preditor das variáveis independentes (dimensões do IPPA-R e do YPI-RE) sobre a variável dependente (dimensão consumo), tendo sido pertinente a criação da variável dummy para a variável sociodemográfica sexo. 


\section{Resultados}

Variância do consumo, dos traços de psicopatia e da vinculação em função da idade e sexo

No sentido de verificar se existem diferenças no consumo em função da idade, realizou- se um Teste $t$ de Student, permitindo verificar que o consumo de substâncias apresenta diferenças estatisticamente significativas consoante as idades. A faixa etária do 15 aos $18 \operatorname{anos}(M=.06, D P=.127)$ apresentou uma média superior ao grupo dos 12 aos 14 anos $(M=.02 ; D P=.089 ; t(176)=-3.04, p=.003)$. Verificou-se, ainda, diferenças significativas na dimensão mentira $(M=1.87 ; D P=.853 ; t(315)=2.40, p=.017)$, na dimensão comunicação à mãe $(M=2.58 ; D P=.303 ; t(173)=2.35, p=.020)$, na atenção/alienação à mãe $(M=2.51$; $D P=.301 ; t(155)=2.05, p=.042)$, na comunicação ao pai $(M=2.42 ; D P=.423 ; t(150)=-$ 3.03, $p=.003)$ e atenção/alienação ao pai $(M=2.44 ; D P=.360 ; t(315)=2.06, p=.040)$, sendo as médias superiores na faixa etária dos 12 aos 14 anos. Os valores das magnitudes de efeito (Partial Eta-squared) obtidos para as variáveis mencionadas anteriormente como significativas, apresentam-se entre 0 e .02, revelando assim uma baixa magnitude de efeito, ou seja, uma proporção de variância entre 0 a $2 \%$ nas variáveis dependentes explicadas por estes grupos de idades (Tabela 1).

Ainda pela realização de um Teste $t$ de Student, comparou-se as pontuações de consumo entre o sexo masculino $(M=.07, D P=.139)$ e feminino $(M=.04, D P=.104 ; t(235)$ $=1.72, p=.086$ ). Foi possível verificar que não existem diferenças significativas no consumo independentemente do sexo do adolescente. Contudo, existem algumas diferenças estatisticamente significativas entre sexos relativamente a outras dimensões avaliadas. São elas o charme falso $(M=2.64 ; D P=.846 ; t(315)=4.20, p=.000)$, a grandiosidade $(M=2.20$; $D P=.910 ; t(247)=5.37, p=.000)$, a mentira $(M=1.93 ; D P=.872 ; t(234)=4.65, p=.000)$, a manipulação $(M=2.17 ; D P=.900 ; t(315)=3.33, p=.001)$, a ausência de remorso 


\begin{tabular}{|c|c|c|c|c|}
\hline \\
\hline & $12-14(g 1)$ & $15-18(g 2)$ & $p$ & $\left(\eta^{2} p\right)$ \\
\hline & $M \pm D P$ & $M \pm D P$ & & \\
\hline Consumo & $.02 \pm .089$ & $.06 \pm .127$ &. $\mathbf{0 0 3}(\mathrm{g} 1<\mathrm{g} 2)$ & .02 \\
\hline Charme Falso & $2.56 \pm .835$ & $2.36 \pm .839$ & $.074(\mathrm{~ns})$ & .01 \\
\hline Grandiosidade & $1.93 \pm .923$ & $1.90 \pm .824$ & $.773(\mathrm{~ns})$ & .00 \\
\hline Mentira & $1.87 \pm .853$ & $1.63 \pm .743$ & $.017(\mathrm{~g} 1>\mathrm{g} 2)$ & .02 \\
\hline Manipulação & $1.94 \pm .827$ & $1.98 \pm .914$ & $.700(\mathrm{~ns})$ & .00 \\
\hline Ausência remorso & $1.93 \pm .778$ & $1.92 \pm .770$ & $.968(\mathrm{~ns})$ & .00 \\
\hline Ausência emotividade & $2.44 \pm .944$ & $2.39 \pm .707$ & $.662(\mathrm{~ns})$ & .00 \\
\hline Frieza emocional & $2.27 \pm 1.078$ & $2.25 \pm .849$ & $.895(\mathrm{~ns})$ & .00 \\
\hline Busca Perigo & $2.55 \pm .955$ & $2.70 \pm .882$ & $.236(\mathrm{~ns})$ & .00 \\
\hline Impulsividade & $2.34 \pm .695$ & $2.48 \pm .805$ & $.178(\mathrm{~ns})$ & .01 \\
\hline Irresponsabilidade & $1.86 \pm .777$ & $1.91 \pm .779$ & $.601(\mathrm{~ns})$ & .00 \\
\hline Mãe confiança & $2.74 \pm .223$ & $2.68 \pm .317$ & $.072(\mathrm{~ns})$ & .01 \\
\hline Mãe comunicação & $2.58 \pm .303$ & $2.47 \pm .427$ & $.020(g 1>g 2)$ & .01 \\
\hline Mãe atenção/alienação & $2.51 \pm .301$ & $2.42 \pm .383$ & $.042(g 1>g 2)$ & .01 \\
\hline Pai confiança & $2.65 \pm .350$ & $2.58 \pm .393$ & $.157(\mathrm{~ns})$ & .01 \\
\hline Pai comunicação & $2.42 \pm .423$ & $2.24 \pm .520$ &. $\mathbf{0 0 3}(\mathrm{g} 1>\mathrm{g} 2)$ & .02 \\
\hline Pai atenção/alienação & $2.44 \pm .360$ & $2.33 \pm .414$ & $.040(g 1>g 2)$ & .01 \\
\hline Pares confiança & $2.58 \pm .384$ & $2.64 \pm .358$ & $.163(\mathrm{~ns})$ & .01 \\
\hline Pares comunicação & $2.42 \pm .468$ & $2.51 \pm .388$ & $.133(\mathrm{~ns})$ & .01 \\
\hline Pares atenção/alienação & $2.35 \pm .364$ & $2.41 \pm .343$ & $.192(\mathrm{~ns})$ & .01 \\
\hline
\end{tabular}

Nota. $M=$ média; $D P=$ Desvio padrão; $\eta^{2} p=$ Partial Eta-squared; ns= não significativo; os negritos representam valores significativos.

$(M=2.09 ; D P=.810 ; t(315)=3.25, p=.001)$, a ausência de emotividade $(M=2.64 ; D P=.794$; $t(266)=4.68, p=.000)$, a frieza emocional $(M=2.66 ; D P=.943 ; t(247)=7.14, p=.000)$, a busca de perigo $(M=2.86 ; D P=.896 ; t(315)=3.37, p=.001)$, a irresponsabilidade $(M=2.07 ; D P=.841 ; t(255)=3.38, p=.001)$, a confiança com o grupo de pares $(M=2.67$; $D P=.364 ; t(315)=-2.60, p=.010)$, e a comunicação com o grupo de pares $(M=2.58$; $D P=.354 ; t(247)=-4.98, p=.000)$. De notar que em todas as dimensões referidas foi o sexo masculino que apresentou a média mais elevada, à exceção da confiança e comunicação com o grupo de pares em que o sexo feminino exibiu uma média superior. Os valores das magnitudes de efeito (Partial Eta- squared) obtidos para as variáveis mencionadas anteriormente como significativas, apresentam-se maioritariamente a um nível baixo a moderado, revelando assim uma proporção de variância intermédia nas variáveis explicadas através do sexo. Contudo é de salientar que, relativamente à dimensão frieza emocional, o sexo masculino foi capaz de explicar $15 \%(\eta 2 p=.15)$ da sua variância e, ainda, de explicar $9 \%(\eta 2 p=.09)$ da variância na grandiosidade (Tabela 2$)$. 
Tabela 2

Análise Diferencial do Consumo e das Dimensões do YPI-RE e do IPPA em Função do Sexo

\begin{tabular}{lcccc}
\hline & Masculino & Feminino & & \\
\cline { 2 - 5 } & $\boldsymbol{M} \pm \boldsymbol{D P}$ & $\boldsymbol{M} \pm \boldsymbol{D P}$ & $\boldsymbol{p}$ & $\left.\boldsymbol{\eta}^{2} \boldsymbol{p}\right)$ \\
\hline Consumo & $.07 \pm .139$ & $.04 \pm .104$ & $.086(\mathrm{~ns})$ & .01 \\
Charme Falso & $2.64 \pm .846$ & $2.25 \pm .800$ & $\mathbf{. 0 0 0}(\mathrm{M}>\mathrm{F})$ & .05 \\
Grandiosidade & $2.20 \pm .910$ & $1.69 \pm .727$ & $\mathbf{. 0 0 0}(\mathrm{M}>\mathrm{F})$ & .09 \\
Mentira & $1.93 \pm .872$ & $1.51 \pm .646$ & $\mathbf{. 0 0 0}(\mathrm{M}>\mathrm{F})$ & .07 \\
Manipulação & $2.17 \pm .900$ & $1.83 \pm .864$ & $\mathbf{. 0 0 1}(\mathrm{M}>\mathrm{F})$ & .03 \\
Ausência remorso & $2.09 \pm .810$ & $1.81 \pm .720$ & $\mathbf{. 0 0 1}(\mathrm{M}>\mathrm{F})$ & .03 \\
Ausência emotividade & $2.64 \pm .794$ & $2.23 \pm .704$ & $\mathbf{. 0 0 0}(\mathrm{M}>\mathrm{F})$ & .07 \\
Frieza emocional & $2.66 \pm .943$ & $1.96 \pm .753$ & $\mathbf{. 0 0 0}(\mathrm{M}>\mathrm{F})$ & .15 \\
Busca Perigo & $2.86 \pm .896$ & $2.52 \pm .878$ & $\mathbf{. 0 0 1}(\mathrm{M}>\mathrm{F})$ & .03 \\
Impulsividade & $2.39 \pm .815$ & $2.48 \pm .756$ & $.333(\mathrm{~ns})$ & .00 \\
Irresponsabilidade & $2.07 \pm .841$ & $1.77 \pm .703$ & $\mathbf{. 0 0 1}(\mathrm{M}>\mathrm{F})$ & .04 \\
Mãe confiança & $2.68 \pm .311$ & $2.70 \pm .288$ & $.458(\mathrm{~ns})$ & .00 \\
Mãe comunicação & $2.45 \pm .421$ & $2.54 \pm .387$ & $.063(\mathrm{~ns})$ & .01 \\
Mãe atenção/alienação & $2.42 \pm .386$ & $2.46 \pm .353$ & $.395(\mathrm{~ns})$ & .00 \\
Pai confiança & $2.60 \pm .376$ & $2.59 \pm .390$ & $.788(\mathrm{~ns})$ & .00 \\
Pai comunicação & $2.34 \pm .458$ & $2.24 \pm .533$ & $.071(\mathrm{~ns})$ & .01 \\
Pai atenção/alienação & $2.38 \pm .386$ & $2.34 \pm .417$ & $.294(\mathrm{~ns})$ & .00 \\
Pares confiança & $2.57 \pm .359$ & $2.67 \pm .364$ & $\mathbf{. 0 1 0}(\mathrm{M}<\mathrm{F})$ & .02 \\
Pares comunicação & $2.35 \pm .442$ & $2.58 \pm .354$ & $\mathbf{. 0 0 0}(\mathrm{M}<\mathrm{F})$ & .08 \\
Pares atenção/alienação & $2.39 \pm .349$ & $2.41 \pm .348$ & $.534(\mathrm{~ns})$ & .00 \\
\hline Not $M$
\end{tabular}

Nota. $M=$ média; $D P=$ Desvio padrão; $\eta^{2} p=$ Partial Eta-squared $M=$ masculino $; F=$ feminino; $n s=$ não significativo; os negritos representam valores significativos.

\section{Associação entre consumo e psicopatia e entre consumo e vinculação}

Partindo do objetivo de analisar as associações entre as dimensões em estudo, elaboram-se análises correlacionais entre as diferentes variáveis. A partir da realização de uma correlação de Pearson (Tabela 3), averiguou-se que o consumo se correlacionou positiva e significativamente (ao nível .01) com todas as dimensões correspondentes aos traços psicopáticos medidos pelo YPI, à exceção da frieza emocional. De ressaltar que as correlações entre o consumo e a busca de Perigo e entre o consumo e a irresponsabilidade foram as que se revelaram superiores, no caso do consumo e busca de perigo a um nível mediano $(r=.415, \mathrm{n}=317, \mathrm{p}<.01)$ e no caso do consumo e irresponsabilidade a um nível elevado $(r=.531, \mathrm{n}=317, p<.01)$. Ou seja, verifica-se relativamente à sobreposição entre as duas primeiras variáveis uma variância compartilhada de $17.22 \%$ e relativamente às segundas uma variância compartilhada de $28.20 \%$ (utilizando o cálculo do coeficiente de determinação). 
Tabela 3

Análise das Correlações Entre a Dimensão Consumo e as Dimensões do YPI-RE

\begin{tabular}{|c|c|c|c|}
\hline & Consumo & $\mathbf{M}$ & DP \\
\hline Charme falso & $.291 * *$ & 2.41 & .841 \\
\hline Grandiosidade & $.222 * *$ & 1.91 & .847 \\
\hline Mentira & $.225 * *$ & 1.69 & .776 \\
\hline Manipulação & $.397 * *$ & 1.97 & .893 \\
\hline Ausência de remorso & $.321 * *$ & 1.92 & .770 \\
\hline Ausência de emotividade & $.260 * *$ & 2.40 & .768 \\
\hline Frieza emocional & .074 & 2.25 & 907 \\
\hline Busca de perigo & $.415 * *$ & 2.66 & .900 \\
\hline Impulsividade & $.365 * *$ & 2.44 & .781 \\
\hline Irresponsabilidade & $.531 * *$ & 1.90 & .778 \\
\hline
\end{tabular}

Analisando as correlações de Pearson entre a dimensão do consumo e as dimensões confiança, comunicação e atenção/alienação referentes à vinculação aos pais e pares é possível verificar que as correlações existentes são negativas e de baixa intensidade (segundo os intervalos de valores sugeridos por Cohen, 1988). Ainda assim, apresentam maioritariamente uma significância ao nível mais elevado (nível .01). O sinal negativo demonstra que as dimensões que estão a ser analisadas na correlação aumentam em direções opostas. Como os valores das correlações obtidas são de baixa intensidade, significa que não existe muita sobreposição entre o consumo e as restantes dimensões, compartilhando pouca percentagem de variância (Tabela 4).

Tabela 4

Análise das Correlações Entre a Dimensão Consumo e as Dimensões do IPPA-R

\begin{tabular}{lccc}
\hline & Consumo & M & DP \\
\hline Confiança mãe & $\mathbf{- . 1 9 8 * *}^{* *}$ & 2.69 & .298 \\
Comunicação mãe & $\mathbf{- . 1 5 2 * *}^{* *}$ & 2.50 & .403 \\
Atenção/alienação mãe & $\mathbf{- . 1 8 8}^{* *}$ & 2.44 & .367 \\
Confiança pai & $\mathbf{- . 1 5 3 * *}$ & 2.59 & .384 \\
Comunicação pai & $\mathbf{- . 1 1 5 ^ { * }}$ & 2.28 & .504 \\
Atenção/alienação pai & -.107 & 2.36 & .404 \\
Confiança pares & $\mathbf{- . 1 4 1 *}$ & 2.63 & .365 \\
Comunicação pares & -.093 & 2.48 & .409 \\
Atenção/alienação pares & $\mathbf{- . 1 6 6 * *}$ & 2.40 & .348 \\
\hline Nota.**Nível de significância de $\mathrm{p}<.01$; os negritos representam valores significativos; $M=$ média; $D P=$ \\
Desvio padrão.
\end{tabular}

\section{Papel preditor da psicopatia e da vinculação nos comportamentos de consumo}

De forma a verificar o papel preditor da psicopatia e da vinculação nos comportamentos de consumo, procedeu-se à realização de análises de regressão múltipla hierárquica, tendo como variável dependente o consumo. Estas análises possibilitam testar 
quais as variáveis independentes que melhor contribuem para a previsão da variável dependente (Pallant, 2005). Optou-se por este método com o intuito de controlar o efeito das variáveis de forma sequencial. Para tanto, introduziram-se 5 blocos, especificamente sexo, traços de psicopatia e vinculação à mãe, vinculação ao pai e vinculação aos pares. A variável sexo foi recodificada em dummy, de modo a identificar e analisar qual dos sexos (0- sexo masculino; 1- sexo feminino) melhor contribui e prediz a variável dependente.

$\mathrm{Na}$ análise de regressão múltipla hierárquica para a variável dependente consumo foram introduzidos 5 blocos. No que respeita ao bloco 1, o sexo (dummy) não contribui de forma significativa para o modelo $\mathrm{F}_{(1,315)}=3.25, p=.073$, embora explique $1 \%$ da variância total $\left(\mathrm{R}^{2}=.010\right)$, contribuindo em $1 \%$ de forma individual para a variância do modelo $\left(\mathrm{R}^{2}\right.$ change $=.010)$.

No bloco 2, observa-se que os traços de psicopatia apresentam um contributo significativo $\mathrm{F}_{(11,305)}=13.96, p=.000$, explicando $33.5 \%$ da variância total $\left(\mathrm{R}^{2}=.335\right)$, contribuindo $32.5 \%$ de forma individual para a variância do modelo $\left(\mathrm{R}^{2}\right.$ change $\left.=.325\right)$. $\mathrm{O}$ bloco 3, demonstra que o IPPA mãe apresenta um contributo significativo $\mathrm{F}_{(14,302)}=11.01$, $p=.000$, sendo capaz de explicar $33.8 \%$ da variância total $\left(\mathrm{R}^{2}=.338\right)$, contribuindo com $0.3 \%$ da variância individual para o modelo $\left(\mathrm{R}^{2}\right.$ change $\left.=.003\right)$.

Relativamente ao bloco 4, verifica-se que o IPPA pai apresenta um contributo significativo $\mathrm{F}_{(17,299)}=9.46, p=.000$, e explica $35 \%$ da variância total $\left(\mathrm{R}^{2}=.350\right)$, contribuindo com $1.2 \%$ da variância individual para o modelo $\left(\mathrm{R}^{2}\right.$ change $\left.=.012\right)$.

No que concerne ao bloco 5, verifica-se que a variável IPPA pares apresenta um contributo significativo $\mathrm{F}_{(20,296)}=8.20, p=.000$, e explica $35.6 \%$ da variância total $\left(\mathrm{R}^{2}=\right.$ $.356)$, contribuindo com $0.7 \%$ da variância individual para o modelo $\left(\mathrm{R}^{2}\right.$ change $\left.=.007\right)$.

A partir da análise individual do contributo de cada uma das variáveis independentes dos blocos, constatou-se que quando o efeito de sobreposição de todas as outras variáveis é estatisticamente controlado, existem duas variáveis que apresentam uma contribuição estatisticamente positiva e significativa $(p<.01)$ enquanto preditoras dos comportamentos de consumo. A dimensão do YPI-RE irresponsabilidade $(\beta=.455)$ foi a que contribuiu mais fortemente para explicar a variável dependente. A significância estatística da presente dimensão foi de .000 e explica isoladamente $10 \%$ (valor obtido por meio da multiplicação do coeficiente de correlação da parte por si próprio e posteriormente colocado em percentagem) da variância no consumo. A dimensão do YPI- RE busca de perigo $(\beta=.178)$, apresentou 
uma significância estatística de .004 , explicando $2 \%$ (valor obtido por meio da multiplicação do coeficiente de correlação da parte por si próprio e posteriormente colocado em percentagem) da variância no consumo. Visto ser a irresponsabilidade que exibe um valor de beta superior, significa que apresenta maior impacto no modelo do que a busca de perigo. É de notar que na correlação de Pearson realizada estas duas dimensões foram as que apresentaram intensidades de correlação mais elevadas com a dimensão consumo. As restantes dimensões constituintes do modelo não revelaram significância estatística, não contribuindo para a previsão da variável dependente (Tabela 5).

Tabela 5.

Regressão Múltipla Hierárquica Para o Consumo

\begin{tabular}{|c|c|c|c|c|c|c|c|}
\hline Consumo & $R^{2}$ & $R^{2}$ Change & $\mathbf{B}$ & $S E$ & $\beta$ & $T$ & $p$ \\
\hline Bloco 1 - Sexo (dummy) & .010 & .010 & -.007 & .014 & -.027 & -.469 & .639 \\
\hline Bloco 2 - YPI-RE & .335 & .325 & & & & & \\
\hline Charme falso & & & .002 & .010 & .013 & 184 & .854 \\
\hline Grandiosidade & & & -.018 & .010 & -.126 & -1.849 & .065 \\
\hline Mentira & & & -.016 & .010 & -.101 & -1.575 & .116 \\
\hline Manipulação & & & .021 & .012 & .157 & 1.800 & 073 \\
\hline Ausência de remorso & & & .004 & 011 & .024 & .350 & .726 \\
\hline Ausência de emotividade & & & -.004 & .010 & -.024 & -.395 & 693 \\
\hline Frieza emocional & & & -.004 & .007 & -.033 & -.612 & .541 \\
\hline Busca de perigo & & & .024 & .008 & .178 & 2.884 & .004 \\
\hline Impulsividade & & & .001 & .010 & .008 & .112 & .911 \\
\hline Irresponsabilidade & & & .071 & .010 & .455 & 6.836 & .000 \\
\hline Bloco 3 - IPPA mãe & .338 & .003 & & & & & \\
\hline Confiança & & & -.024 & .034 & -.059 & -.694 & 488 \\
\hline Comunicação & & & .036 & .027 & .122 & 1.353 & .177 \\
\hline Atenção/alienação & & & -.030 & .028 & -.091 & -1.048 & .296 \\
\hline Bloco 4 - IPPA pai & .350 & .012 & & & & & \\
\hline Confiança & & & -.010 & .030 & -.033 & -.342 & .733 \\
\hline Comunicação & & & -.034 & .024 & -.143 & -1.430 & .154 \\
\hline Atenção/alienação & & & .047 & .026 & .156 & 1.776 & 077 \\
\hline Bloco 5 - IPPA pares & .356 & .007 & & & & & \\
\hline Confiança & & & -.040 & .029 & -.122 & -1.374 & 171 \\
\hline Comunicação & & & .004 & .026 & .013 & .151 & .880 \\
\hline Atenção/alienação & & & .020 & .023 & .059 & .884 & .378 \\
\hline
\end{tabular}

\section{Discussão}

O presente estudo objetivou identificar o papel da vinculação aos pais e pares e de um conjunto de traços psicopáticos sobre o consumo de drogas. Assim, procurou explorarse de que forma o consumo difere em função do sexo e idade do adolescente. Procurou-se 
também perceber se o consumo e as várias dimensões do IPPA-R e do YPI-RE se associavam entre si e, por fim, analisar o papel preditor do sexo, do IPPA-R e do YPI-RE no consumo.

Face aos resultados, verificou-se no que respeita à idade que foram encontradas diferenças no consumo, apontando para os adolescentes em idade mais avançada (15 aos 18 anos) como os consumidores em maior proporção. Tal como comprovado por Naia, Simões e Matos (2007) num estudo realizado com 6131 sujeitos com idades compreendidas entres os 11 e os 25 anos, na generalidade os adolescentes mais novos referem um menor envolvimento com substâncias ilícitas comparativamente aos adolescentes mais velhos. No estudo de Vinagre e Lima (2006) com 585 adolescentes de escolas públicas de Lisboa, com idades compreendidas entre os 15 e os 21 anos, foram os adolescentes de 17 e 18 anos ou mais (ou seja, os mais velhos) os que referiram maior envolvimento nos diferentes tipos de consumo. A perceção dos riscos associados aos comportamentos de consumo também diminuem com a idade. Assim, não parece surpreendente o facto da pontuação no consumo ser superior nos adolescentes mais velhos, visto estes apresentarem menores estimativas de risco.

O valor superior obtido relativamente às dimensões comunicação e atenção/alienação às figuras parentais dos adolescentes entre os 12 e os 14 anos de idade, comparativamente ao grupo dos 15 aos 18 anos, poderá ser explicado pelo facto de se encontrarem numa fase inicial da adolescência, logo num momento de transição entre a diminuição da vinculação aos pais e aumento dos laços vinculativos ao grupo de pares, enquanto que o grupo dos 15 aos 18 anos já se apresenta numa fase mais avançada da adolescência, exibindo uma vinculação mais forte com o grupo de pares, sendo de prever que as dimensões da vinculação em avaliação já estejam mais fortalecidas para com estes (Ferronha et al., 2008).

Verificou-se que na amostra em estudo não foram encontradas diferenças significativas no consumo de substâncias no que respeita ao sexo do adolescente. $O$ mesmo não se verificou num estudo realizado por Monteiro, Araújo, Sousa, Martins e Silva (2012) em escolas públicas com 196 adolescentes, em que os resultados obtidos apresentaram significância estatística quanto ao sexo, sendo o sexo masculino a apresentar consumos em maior proporção. Efetivamente, a literatura e as estatísticas apontam para na generalidade os valores de consumo se apresentarem superiores no sexo masculino. Também, no estudo realizado por Tavares et al. (2001), com uma população de estudantes de idades 
compreendidas entre os 10 e os 19 anos de idade, constatou-se, novamente, os consumos em maior escala no sexo masculino relativamente ao feminino.

Verificou-se, ainda, que o sexo masculino apresentou uma média mais elevada em todo o conjunto de traços de psicopatia avaliados. Perante este resultado é possível hipotetizar que os rapazes estarão mais predispostos a apresentar um conjunto de traços psicopáticos, e possivelmente um tipo de personalidade mais antissocial. Efetivamente, Rutherford, Alterman e Cacciola (1996), realizaram um estudo com consumidores de heroína ( 251 homens e 68 mulheres) no sentido de perceber a prevalência de psicopatia entre estes. Os resultados apontaram para o facto do sexo feminino apresentar pontuações mais baixas nos resultados do PCL-R do que o sexo masculino. Também, num estudo realizado por Grann (2000), com 36 indivíduos do sexo feminino e 36 indivíduos do sexo masculino num hospital psiquiátrico forense na Suécia, foi possível constatar, a partir da aplicação da escala PCL-R, que 31\% dos homens revelaram existência de psicopatia, comparativamente a $11 \%$ nas mulheres. Embora o estudo tenha sido realizado na faixa etária da adultícia, é de esperar que esses mesmos traços associados à psicopatia já se tenham começado a desenvolver e consolidar anteriormente, nomeadamente na adolescência. Ainda, Dolan e Vollm (2009) apontam para o facto da prevalência e incidência da psicopatia no sexo masculino apresentar-se mais do dobro do que aquela que se verifica no sexo feminino. Seguindo a lógica do sexo masculino pontuar de forma superior nos traços de psicopatia, e estando estes e o consumo de substâncias positivamente correlacionados, seria de esperar que o sexo masculino pontuasse de forma superior ao nível do consumo. Contudo, tal como já foi mencionado anteriormente, o mesmo não foi possível verificar através das análises realizadas no presente estudo.

A magnitude de efeito significativa apresentada pela frieza emocional no sexo masculino, permite corroborar os achados de Grann (2000) que num estudo realizado com 72 indivíduos (de ambos os sexos) de um hospital psiquiátrico, concluiu que a falta de empatia se apresenta como um dos traços discriminadores da psicopatia no sexo masculino. Esta falta de empatia poderá ser justificativa da existência de frieza emocional em maior grau, ou vice-versa. Assim, é possível que se influenciem mutuamente. Também Warren et al. (2003) defendem que o sexo masculino apresenta maior insensibilidade emocional, podendo este achado justificar a magnitude de efeito relativamente significativa encontrada no presente estudo para o sexo masculino no que respeita à ausência de emotividade. 
O sexo feminino exibiu uma média superior nas dimensões da comunicação e confiança aos pares, o que poderá significar que apresentam maior ligação ao grupo de pares e valorização deste. Tal como referido pela literatura, para as raparigas, efetivamente o grupo de pares constitui-se como um espaço de intimidade onde trocam confidências, receios e expectativas. Já os adolescentes do sexo masculino não exteriorizam com o grupo de pares os seus conflitos, medos, dúvidas e problemas com a mesma facilidade, visto que para eles significaria entrar em confronto com o modelo de identidade masculina. Assim, verifica-se uma diferença relevante no lugar que o grupo de pares ocupa para cada um dos sexos (Romanelli \& Prieto, 2002).

Relativamente ao papel das duas variáveis independentes em estudo (medidas a partir do IPPA-R e do YPI-RE), apurou-se que foi o YPI-RE que apresentou correlações superiores, positivas e mais significativas com o consumo (DAST). Isto permite corroborar alguns estudos anteriormente citados, tal como o estudo de Fonseca (2013) que afirma a elevada correlação entre consumo e comportamentos antissociais e o desenvolvido por Lühring et al. (2014) que, também, revelou uma elevada correlação entre traços de psicopatia e consumo. Apurou-se, ainda, a existência de uma associação negativa entre as componentes de vinculação aos pares e figuras parentais (dimensões confiança, comunicação e atenção/alienação) e o consumo, o que permite concluir que a vinculação e o consumo aumentam em sentido inverso. Os valores negativos obtidos, revelam que quanto maior e mais adaptativas forem as dimensões da vinculação avaliadas, menor serão os comportamentos de consumo. Efetivamente, quanto menor a relação de proximidade e ligação às figuras parentais maior a probabilidade de consumir e vice-versa. Tais resultados, corroboram o estudo realizado por Ferronha et al. (2008) e confirmam, também, o que foi proferido por Gonçalves e Pereira (2011) relativamente à relevância que os padrões de confiança e comunicação têm nos comportamentos de consumo. Mais se aponta, que um forte suporte e identificação familiar e um envolvimento afetivo positivo constituem-se como importantes fatores de proteção para o adolescente, sendo que o facto dos jovens sentirem preocupação por parte dos pais e proximidade com estes diminui a probabilidade dos comportamentos de risco (Silliman, 1994). Este autor afirma, ainda, que os jovens que sentem-se próximos dos pais, que sentem que a família gosta e se preocupa com eles e que estão satisfeitos com as suas relações familiares têm menos probabilidade de entrar em comportamentos de risco. No que respeita ao grupo de pares, salienta-se que, não importa meramente o estabelecimento de uma vinculação adequada mas também, tal como proferido 
pela literatura, o facto do grupo ao qual o adolescente pertence funcionar como facilitador (no caso de consumir) ou como protetor (no caso de não consumir ou desaprovar os comportamentos de consumo) no que respeita a adição. Ou seja, espera-se que o adolescente procure agir de forma análoga ao grupo a que pertence (Brandão, 2013). No caso da presente amostra, possivelmente, os grupos a que os adolescentes inquiridos pertenciam não apresentavam na sua maioria comportamentos de consumo, justificando assim a associação negativa deste com a vinculação ao grupo de pares.

Os valores obtidos na regressão hierárquica múltipla no que respeita aos traços psicopáticos, permitiram verificar que estes, isoladamente, apresentam uma percentagem significativa preditora do consumo de substâncias. Um estudo realizado numa população de 360 reclusos do sexo masculino demonstrou de forma significativa a associação entre a existência de psicopatia (medida por meio do PCL-R) e consumo de álcool, barbitúricos, opiáceos e anfetaminas. Contudo, existiram substâncias, como cannabis e cocaína, que não apresentaram associações significativas com a psicopatia. Foram ainda os psicopatas que, nesse mesmo estudo, revelaram níveis de consumo mais consideráveis (Smith \& Newman, 1990).

Mais especificamente, os resultados do presente estudo permitiram verificar que o consumo é predito positiva e significativamente pelas dimensões do YPI-RE irresponsabilidade e busca de perigo. Nesta medida, parece que o facto de estarem patentes nos adolescentes estes dois traços de psicopatia aumenta a probabilidade de consumo. Efetivamente, a busca de perigo e a irresponsabilidade foram não só os traços psicopáticos que se apresentaram como maiores preditores do consumo, como também os mais significativos na correlação com este. Isto poderá relacionar-se com a tendência natural do adolescente em orientar-se pelo princípio do prazer, logo tudo o que esteja relacionado com um certo risco e procura pelo perigo ou com o ato de fugir às suas responsabilidades apresentar-se como tentador. Daí não ser de estranhar os valores significativos obtidos nestas dimensões (Feijó \& Oliveira, 2001). Além de que, a atração pelo risco (busca de perigo) e por novas experiências, como por exemplo as drogas, apresenta-se como uma das características distintivas dos adolescentes, sendo facilmente justificável a maior associação encontrada entre busca de perigo e irresponsabilidade com o consumo (Fonseca, 2013).

Relativamente à vinculação e, contrariamente à psicopatia, os resultados obtidos mostram efetivamente o efeito pouco preditor dos blocos da vinculação sobre o consumo, 
pois esta (se estabelecida de forma adequada) funciona normalmente como fator protetor. Assim se explicar a baixa percentagem do efeito preditor destes blocos sobre o consumo. Mais se acrescenta que, individualmente nenhuma das dimensões vinculativas constituintes dos blocos apresentou um valor preditivo significativo sobre o consumo. Este resultado permite corroborar o previsto pela literatura que afirma que bons vínculos afetivos, bons padrões de comunicação e existência de confiança se opõem ao consumo (Gonçalves \& Pereira, 2011). Por sua vez, como Ferronha et al. (2008) comprovaram no seu estudo, adolescentes consumidores apresentavam efetivamente uma vinculação mais insegura às figuras parentais. Relativamente ao grupo de pares, estes efetivamente apresentam um poder significativo sobre os comportamentos adotados pelo adolescente, agindo este normalmente em conformidade com o grupo a que pertence (Dietz et al., 2011; Brandão, 2013). Na presente amostra, este poder não se verificou relativamente às dimensões da vinculação sobre o consumo, uma vez que estas não se revelaram preditoras dos comportamentos de adição. Assim, espera-se que os adolescentes da amostra não fizessem parte de grupos consumidores, tendo por base os resultados obtidos e aquilo que é proferido pela literatura.

\section{Implicações práticas, limitações e propostas para estudos futuros}

De modo a finalizar o presente estudo, importa ressaltar que o mesmo pretendeu contribuir para a clarificação e ampliação dos conhecimentos teóricos e práticos no que respeita ao papel da vinculação às figuras parentais e ao grupo de pares nos comportamentos aditivos por parte dos adolescentes e, ainda, ao papel dos traços psicopáticos.

Neste sentido, e de modo a realizar-se um balanço final desta investigação, torna-se pertinente salientar as suas principais implicações e limitações de que padeceu. As implicações práticas inerentes ao presente estudo passam pelo contributo positivo na compreensão da importância da qualidade da vinculação estabelecida às figuras de referência (mãe, pai e pares) como fator protetor de comportamentos de risco, nomeadamente dos comportamentos aditivos. De facto, torna-se importante compreender a criação destes vínculos afetivos por parte do adolescente visto que os resultados da presente investigação sugerem que uma vinculação pautada por uma boa comunicação e baseada em confiança e atenção parecem funcionar como fator protetor nos comportamentos de consumo. Além de que, tal como mencionado pela literatura, as relações estabelecidas com as figuras significativas funcionam como pilar para tudo o que envolve a vida do adolescente e para as suas tomadas de decisões. 
Outra implicação prática relativa à presente investigação remete para a importância da deteção precoce de comportamentos sinalizadores da existência de traços associados à psicopatia, que poderão funcionar como impulsionadores do consumo. Efetivamente, e tal como comprovado no presente estudo e noutros estudos já realizados, a psicopatia apresentase como consideravelmente preditora do consumo de substâncias. Face ao exposto, esperase que os resultados obtidos e as conclusões elaboradas permitam contribuir para uma maior consciencialização relativamente à temática do consumo de drogas na faixa etária da adolescência e a relevância de certos intervenientes que poderão funcionar ora como fatores protetores ora como fatores de risco para esses consumos.

Tendo em conta a associação negativa encontrada entre o consumo e a vinculação, torna-se pertinente trabalhar o mais precocemente possível com as figuras parentais competências ao nível das dimensões da vinculação abordadas (comunicação, confiança, atenção/alienação), na tentativa dos laços vinculativos estabelecidos serem o mais positivos e adequados, funcionando como fator protetor de comportamentos de risco. Chama-se, também, especial atenção para que seja colocado o máximo ênfase em determinados comportamentos possíveis sinalizadores de psicopatia nesta faixa etária, possibilitando uma intervenção atempada que impedirá o aparecimento de outro tipo de comportamentos associados, como a adição. Umas das formas de o fazer, poderá ser por meio da realização de um acompanhamento próximo e pormenorizado aos jovens nestas idades tao vulneráveis a tudo que os rodeia. Mais especificamente em relação às drogas, as campanhas de sensibilização para adoção de bons comportamentos e evitação de fatores de risco por parte dos jovens poderão, também, surtir efeitos positivos. Assim, estudos como o presentemente realizado, poderão servir de ferramenta de auxílio para as campanhas de alerta e sensibilização, quer para os adolescentes, como para as figuras parentais, comunidade educativa e sociedade em geral, na tentativa de chamar atenção para questões como as das variáveis estudadas e a influência que estas podem apresentar no consumo de drogas.

É de salientar a existência de algumas limitações, nomeadamente o tamanho da amostra, que não é representativa da população portuguesa. Assim, em investigações futuras seria relevante aumentar o grupo amostral. Seria, ainda, interessante realizar uma recolha noutro tipo de instituições de ensino, como escolas privadas, escolas consideradas problemáticas - escolas tipo TEIP (Territórios Educativos de Intervenção Prioritária), entre outras. Outra limitação que se aponta é o facto de este ser um estudo transversal, recolhido 
num único momento do tempo. Todavia, tendo em conta o caráter crónico muitas vezes associado ao consumo seria pertinente efetuar uma nova recolha da mesma amostra em diferentes períodos do tempo (perspetiva longitudinal), efetuando uma comparação entre os resultados obtidos, podendo estes acrescentar novas informações pertinentes para a temática em estudo, bem como o estabelecimento de relações de causalidade. No futuro, tornar-se-ia benéfico replicar este estudo simultaneamente com uma escala que possibilitasse perceber os diferentes tipos de droga consumidos, em que proporção e circunstâncias, permitindo compreender de forma mais explícita o consumo por parte dos adolescentes e confrontar com as estatísticas obtidas até ao momento através de estudos já realizados por outros autores e entidades competentes que trabalham na área. Mais se acrescenta, que seria interessante estudar também na presente amostra a correlação entre psicopatia e vinculação, uma vez que já existem estudos a comprovar a existência desta associação. E, ainda, estudar o efeito preditor do consumo de substâncias sobre os traços psicopáticos (predição oposta àquela que foi realizada nesta investigação).

\section{Conclusão}

É sabido que a prevalência de consumo de drogas ilícitas na faixa etária da adolescência é considerável e apresenta um início cada vez mais precoce. Associado a este consumo advêm prejuízos para o crescimento e desenvolvimento que se arrastam até à vida adulta (Monteiro et al., 2012). Assim, é imprescindível um maior conhecimento relativamente a fatores que poderão funcionar como facilitadores deste consumo e a identificação atempada dos mesmos.

Na presente investigação, as variáveis em análise foram capazes de explicar de forma considerável a variância no consumo de drogas por parte dos adolescentes da amostra em estudo. Verificou-se uma maior correlação entre os traços psicopáticos e o consumo de substâncias do que entre este e a vinculação, como já seria de prever pela literatura. É possível constatar que a presença de uma menor vinculação às figuras significativas ou uma vinculação desajustada, esteja relacionada com o consumo de substâncias, embora os resultados obtidos não tenham revelado valores intensos entre esta correlação. De forma mais substancial verificou-se perfeitamente o efeito preditor dos traços psicopáticos sobre o consumo. Mais se acrescenta, ser o sexo masculino a revelar uma pontuação superior no que respeita a estes traços. 
Conclui-se, que são fundamentais as crenças apresentadas pelos adolescentes relativas ao facto das figuras vinculativas que os rodeiam aprovar ou desaprovar o comportamento de consumo. Assim, o adolescente rodear-se de um grupo que não aprove este tipo de comportamentos será imprescindível, sem esquecer o poder fundamental das figuras parentais que funcionam como modelos comportamentais (Brandão, 2013; Dietz et al., 2011). Efetivamente, os comportamentos e estilos parentais adotados afetam de forma diversa e significativa o adolescente no que respeita ao desenvolvimento de certas características relacionadas com as questões sociais, cognitivas, emocionais e filiação no grupo de pares, podendo funcionar como fator de proteção ou como fator de risco relativamente à adoção de determinados comportamentos. A qualidade de vida familiar apresenta um peso considerável na prevenção de comportamentos de risco no adolescente, como o consumo de drogas (Camacho \& Matos, 2006). Além do mais, as circunstâncias de vida a nível familiar e social e as vivências infantis e juvenis associadas a fatores biológicos podem, também, despoletar o aparecimento de psicopatia (Gomes \& Almeida, 2010). Com o surgimento da psicopatia, ou de traços caraterísticos desta, aumentam os fatores de riscos associados aos comportamentos aditivos. Assim, importa investir num padrão de vinculação positivo, como meio não somente da prevenção do consumo, mas também preventivo relativamente à questão da psicopatia. Ate porque, tal como proferido por Hare (1991), a reduzida empatia e vinculação às figuras significativas, apresenta-se como uma das características frequentemente associadas à psicopatia.

As instituições de ensino apresentam, também, um papel preponderante no que respeita à temática das drogas e é fundamental existir uma intervenção precoce junto da comunidade escolar (realização de programas de prevenção do uso de drogas e debates sobre a temática e perspetivas em relação ao futuro) no sentido de sensibilizar e criar uma maior consciencialização sobre o consumo e as consequências advindas do mesmo. Importa ainda, perceber as ideias e significados que os adolescentes atribuem aos diferentes comportamentos de consumo, bem como experiências já vivenciadas, criando posteriormente interação e discussão entre grupos para tentar encontrar possíveis fatores protetores, sem valorizar de forma excessiva os efeitos negativos do consumo pois, caso contrário, as intervenções poderão não ter o sucesso desejado e não levar á mudança de comportamentos. 
Estudos semelhantes à presente investigação devem continuar a ser realizados, não só para permitir obter um maior conhecimento sobre o consumo na faixa etária da adolescência, como também possibilitar realizar uma intervenção atempada em casos considerados de risco. Além de que este consumo se torna, ainda, mais problemático quando associado a outras questões como a psicopatia. 


\section{Referências}

Ainsworth, M., \& Bowlby, J. (1991). An ethological approach to personality development. American Psychologist, 46(4), 333-341.

Armsden, G., \& Greenberg, M. (1987). The Inventory of Parent and Peer Attachment: Individual differences and their relationship to psychological well-being in adolescence. Journal of Youth and Adolescence, 16(5), 427-454. https://doi.org/10.1007/BF02202939

Bandura, A. (1977). Self-efficacy: towards a unifying theory of behavioral change. Psychological Review, 84(2), 191-215.

Brandão, M. (2013). A formação humana na adolescência numa perspectiva do não uso de drogas. Revista Polyphonía, 24(1), 117-134.

Camacho, I., \& Matos, M. (2006). Práticas parentais, escola e consumo de substâncias em jovens. Psicologia, Saúde \& Doenças, 7(2), 317-327.

Campbell, M. A., Porter, S., \& Santor, D. (2004). Psychopathic traits in adolescent

offenders: An evaluation of criminal history, clinical, and psychosocial correlates.

Behavioral Sciences and the Law, 22(1), 23-47. https://doi.org/10.1002/bsl.572

Cohen, J. (1988). Statistical power analysis for the behavioral sciences $\left(2^{\text {nd }}\right.$ Ed.). Hillsdale, NJ: Lawrence Erlbaum Associates.

Dietz, G., Santos, C., Hildebrandt, L., \& Leite, M. (2011). As relações interpessoais e o consumo de drogas por adolescentes. Revista Eletrônica Saúde Mental Álcool e Drogas, 7(2), 85-91. https://doi.org/10.11606/issn.1806-6976.v7i2p85-91

Dolan, M., \& Vollm, B. (2009). Antissocial personality disorder and psychopathy in women: A literature review on reliability and validity of assessment instruments. International Journal of Law and Psychiatry, 32, 2-9.

Feijó, R., \& Oliveira, E. (2001). Comportamento de risco na adolescência. Jornal de Pediatria, 77(2), 125-134.

Ferreira, F., \& Pinho, P. (2009). Psicanálise e teoria da vinculação. Portal dos psicólogos.

Ferronha, C., Teixeira, E., \& Souto, T. (2008). Vinculação em adolescentes toxicodependentes. International Journal of Developmental and Educational Psychology. Revista INFAD de Psicología, 1(1), 191-200.

Ferronha, J., Almeida, A., Oliveira, L., Sousa, J., \& Sousa, V. (2014). Estudo da vinculação e da empatia em adolescentes institucionalizados com acompanhamento psicológico no PIAC (plano integrado de apoio à comunidade). International Journal of Developmental and Educational Psychology. Revista INFAD de Psicología, 1(1), 327-338. https://doi.org/10.17060/ijodaep.2014.n1.v1.378

Ferros, L. (2003). Jovens, drogas e famílias - uma breve revisão da literatura. Revista Toxicodependências, 9(2), 71-83.

Fonseca, A. (2010). Consumo de droga durante a adolescência em escolas portuguesas. Psychologica, 2, 163-183. https://doi.org/10.14195/1647-8614_47-1_8

Fonseca, A. (2013). Consumo de drogas e comportamentos antissociais na adolescência: Que relação?. Revista Portuguesa de Pedagogia, 47(1), 157-176. https://doi.org/10.14195/1647-8614_47-1_8

Gálvez, B., Fernández, L., Manzanaro, M., Valenzuela, M., \& Lafuente, M. (2010). Validación española del drug abuse screening test (DAST-20 y DAST-10). Health and addictions/Salud y drogas, 10(1), 35-50. https://doi.org/10.21134/haaj.v10i1.35

Gomes, C., \& Almeida, R. (2010). Psicopatia em homens e mulheres. Arquivos Brasileiros de Psicologia, 62(1), 13-21. 
Gonçalves, A., \& Pereira, M. (2011). Variáveis familiares e toxicodependência. Sociedade Brasileira de Psicologia Hospitalar, 14(2), 228-251.

Grann, M. (2000). The PCL-R and gender. European Journal of Psychological Assessment, $16,147-149$.

Gullone, E., \& Robinson, K. (2005). The Inventory of Parent and Peer Attachment - Revised (IPPA-R) for children: A psychometric investigation. Clinical Psychology and Psychotherapy, 12(1), 67-79.

Hare, R. (1991). Manual for the Hare Psychopathy Checklist-Revised. Toronto: MultiHealth Systems.

Kandel, D. (1975). Stages in adolescent involvement in drug use. Science, 190(4217), $912-$ 914.

Lühring, G., Gauer, G., Vasconcellos, S., Davoglio, T., Silva, L., \& Navarrette, S. (2014). Correlação entre traços de psicopatia e abuso de drogas em uma amostra de adolescentes brasileiros em conflito com a lei. Saúde e Desenvolvimento Humano, 2(1), 29-39.

Machado, T., \& Figueiredo, T. (2010). Vinculação a pais, pares e professores - estudos com o IPPA-R para crianças do ensino básico. Psychologica, 53, 27-45.

Marôco, J. (2007). Análise estatística com utilização do SPSS ( $3^{\mathrm{a}}$ Ed.). Lisboa: Sílabo.

Marôco, J. (2014). Análise das equações estruturais: Fundamentos teóricos, software \& aplicações $\left(2^{\mathrm{a}} \mathrm{Ed}\right.$.). Portugal: ReportNumber.

McCord, W., \& McCord, J. (1959/1964). The psychopath: An essay on the criminal mind. Princeton, NJ: Van Nostrand Company.

Monteiro, C., Araújo, T., Sousa, C., Martins, M., \& Silva, L. (2012). Adolescentes e o uso de drogas ilícitas: Um estudo transversal. Revista Enfermagem, 20(3), 344.

Mulaik, S., James, L., Alstine, J., Bennett, N., Lind, S., \& Stilwell, C. (1989). Evaluation of Goodness-of-Fit Indices for structural equation models. Psychological Bulletin, 105(3), 430-445. https://doi.org/10.1037/0033-2909.105.3.430

Naia, A., Simões, C., \& Matos, M. (2007). Consumo de substâncias na adolescência. Toxicodependências, 13(3), 23-30.

Pallant, J. (2005). SPSS survival manual: A step by step guide to data analysis using SPSS for Windows (12 ${ }^{\text {th }}$ Ed.). Austrália: Allen \& Unwin.

Pechansky, F. (2001). Modelo teórico de exposição a risco para transmissão do vírus HIV em usuários de drogas. Revista brasileira de psiquiatria, 23(1), 41-47.

Romanelli, G., Prieto, D. (2002). Adolescentes do sexo feminino: Família, grupo de pares e relações afetivas. Paidéia, 12(22), 57-68. https://doi.org/10.1590/S0103$\underline{863 X 2002000100006}$

Rutherford, M. J.; Alterman, A. I. \& Cacciola, J. S. (1996). "Reliability and validity of the Revised-Psychopathy Checklist in opiate and cocaine addicted women". In: David J. Cook; Adelle E. Forth, Joseph Newman and Robert Hare (Eds.), International Perspectives on Psychopathy (136-141). London: The British Psycological Society.

Salekin, R. (2002). Psychopathy and therapeutic pessimism: clinical lore or clinical reality? Clinical Psychology Review, 22(1), 79-112.

Salekin, R., \& Frick, P. (2005). Psychopathy in children and adolescents: The need for a developmental perspective. Journal of Abnormal Child Psychology, 33(4), 403-409.

Salekin, R., \& Lynam, D. (2010). Child and Adolescent Psychopathy: An Introduction. In R. Salekin. \& D. Lynam (Ed.), Handbook of child \& adolescent Psychopathy (pp. 389-414). New York: Guilford Press. 
Santos, A. (2013). Morbilidade Psicológica, Comportamentos, Conhecimentos e Perceções de risco para o VIH na Toxicodependência (Dissertação de mestrado não publicada). Universidade Católica Portuguesa, Braga.

Silliman, B. (1994). Resiliency research review: Conceptual \& research foundations.

Simões, M., \& Relva, I.C. (2019). Youth Psychopatic Inventory Traits Reconstruted (Unpublished manuscript). Departamento de Educação e Psicologia, Universidade de Trás-os-Montes e Alto Douro.

Simões, M., Lara, S., Lourenço, A., \& Martins, J. (2018, Setembro). Adaptação e análise da estrutura interna na vinculação a pais e pares (IPPA-R) em adolescentes portugueses. Paper apresentando no $4^{\circ}$ Congresso da Ordem dos Psicólogos Portugueses, Braga.

Skinner, H. (1982). The drug abuse screening test. Addictive Behaviors, 7, 363-371.

Smith, S. S. \& Newman, J. P. (1990). Alcohol and drug abuse-dependence disorders in psychopathic and nonpsychopathic criminal offenders. Journal of Abnormal Psychology, 99(4), 430-439.

Soeiro, C., \& Gonçalves, R. (2010). O estado de arte do conceito de psicopatia. Análise Psicológica, 28(1), 227-240.

Vinagre, M., \& Lima, M. (2006). Consumo de álcool, tabaco e droga em adolescentes: Experiências e julgamentos de risco. Psicologia, Saúde \& Doenças, 7(1), 73-81.

Warren, J., South, S., Burnette, M., Rogers, A., Friend, R., Bale, R., \& Patten, I. (2003). Understanding the risk factors for violence and criminality in women: The concurrent validity of the PCL-R and HCR-20. International Journal of Law and Psychiatry, 28, 269-289. 